\title{
UNA PROPUESTA INNOVADORA EN EL PROCESO DE ENSEÑANZA-APRENDIZAJE DE TEMAS TRANSVERSALES EN INTRODUCCIÓN A LA BIOLOGÍA
}

Lic. Natalia SILVA ${ }^{1}$; Dra. Cristina ARMÚA; Dra. Paula SONEIRA

Palabras claves: enseñanza para la comprensión, evolución, nuevas tecnologías de la información.

\section{RESUMEN}

El presente trabajo se realizó con los educandos de primer año de la Asignatura Introducción a la Biología. Con el propósito de ir mejorando los resultados finales de los cursantes de la misma, se comenzó a implementar el uso de las TICS, en la metodología enseñanza para la comprensión, que veníamos aplicando secuencialmente.A fin de contar con un diagnóstico en relación con el uso de TICS en la población de ingresantes a la asignatura Introducción a la Biología, se elaboró una encuesta semi-estructurada que incluyó 25 indicadores. Dicho instrumento fue aplicado a una muestra de 128 alumnos regulares de la cohorte 2017. De los resultados obtenidos se extrae que el uso del aula virtual de la asignatura es con una frecuencia regular por el 50-75\% de los alumnos. Además, > 75\%de los educandos utilizan a diario internet y la aplicación youtube. En este contexto se propusieron los siguientes objetivos: 1-Analizar el uso de las herramientas tecnológicas en los procesos de enseñanza de aprendizaje en el marco de la metodología de Enseñanza para la Comprensión y 2- Evaluar la aplicación de simuladores en la construcción de conocimiento asociado a los procesos de evolución.Considerando que uno de los principios unificadores de la biología es la Evolución, se incorporó la innovación con la aplicación de simuladores, para el desarrollo de este contenido trasversal al programa vigente.El uso de esta herramienta permitió trabajar con un enfoque sistémico, gradualmente en el proceso de enseñanza aprendizaje, lo que permitió obtener mejores desempeños de los alumnos en las evaluaciones parciales y en consecuencia en los exámenes finales presentando propuestas claras de integración y comprensión de los ejes estructurantes de la asignatura. 


\section{INTRODUCCION}

El presente trabajo se realizó con los educandos de la Asignatura Introducción a la Biología que se dicta en el primer cuatrimestre del primer año de las carreras Profesorado de Biología y Licenciatura en Ciencias Biológicas de la Facultad de Facultad de Cs. Exactas y Naturales y Agrimensura (Universidad Nacional del Nordeste). La asignatura es de régimen regular, con examen final. Cada año ingresan alrededor de 200-250 alumnos provenientes de un amplio espectro de orientaciones en el nivel secundario. E1 75\% aproximadamente provienen de colegios orientación biológica, el resto corresponden a orientaciones en humanidades y económicas principalmente. El lugar de origen es en general de las ciudades principales de la región nordeste de la Argentina, con mayor preponderancia de las provincias de Chaco y Corrientes. En general, cerca del $98 \%$ del total de la cohorte de ingresantes se corresponde con alumnos que provienen del nivel medio, con un mínimo porcentaje de alumnos provenientes de otras carreras universitarias o recursantes de las dos $\mathrm{ca}^{-}$ rreras mencionadas.

Desde el año 2014, con el propósito de mejorar los niveles de desempeño de los alumnos y reducir la deserción universitaria, se realizó una revisión en las estrategias de enseñanza y comenzamos a implementar progresivamente la metodología, enseñanza para la comprensión (EpC), cuyo objetivo central era la búsqueda de propuestas que permitan pensar, reflexionar, tanto a los docentes como a los alumnos participando activamente en la construcción y la comprensión del conocimiento (Pogré, 2009). Los marcos teóricos se desarrollan con un enfoque integrador teórico-práctico en todas las unidades temáticas y evaluaciones de proceso (parciales) y sumativas (finales). En dichos espacios se pone énfasis en los tópicos generativos que orientan las propuestas didácticas a la participación activa e integradora motivando a la comprensión de los ejes estructurantes para facilitar la transposición a situaciones nuevas de aprendizaje. Por otro lado, la población del alumnado se organiza anualmente en comisiones de trabajos prácticos (30-40 alumnos). En el marco del proceso de integración de las herramientas Tics a la metodología de enseñanza para la comprensión, se implementa regularmente una variedad de tecnologíasen la asignatura, que van desde plataforma aula virtual, animaciones audiovisuales, el uso de celulares para procesar imágenes y fotografías, videos y simulación de procesos de la naturaleza. En los últimos años, la escuela se ha visto "bombardeada" por las nuevas tecnologías de la información (TIC). Esta presencia ha planteado una serie de desafíos relacionados con la posibilidad de incorporar a las TIC como herramientas que asistan y enriquezcan la enseñanza. (Salomón, 2012). Estudios recientes sugieren que para que una iniciativa de integración de tecnología sea exitosa en ámbitos educativos debe estar claramente conectada a objetivos educativos que trasciendan el uso de las TIC y que tengan un significado profundo para la educación (Manso, M. et al, 2011). 


\section{DESARROLLO}

En este contexto a fin de contar con un diagnóstico en relación con el uso de Tics en la población de ingresantes a la asignatura Introducción a la Biología, se elaboró una encuesta semi-estructurada que incluyó 25 indicadores (Tabla 1). Dicha encuesta fue realizada a una muestra de 128 alumnos regulares de la cohorte 2017. De los resultados obtenidos se extrae que entre las Tics de menor frecuencia $(<25 \%)$ de uso se encuentran los foros on line, los programas de simulación (no lúdicos), consultas a google académico, el uso de PREZI y la carga de contenidos en espacios Wikis.

Por otro lado, el uso del aula virtual de la asignatura (entorno Moodle) es utilizada con una frecuencia regular (2 a 3 veces/ semana) por el 50-75\% de los alumnos. Dentro del cuartil 4 (> 75\%) se encuentran: uso diario de internet en general, y en particular la aplicación youtube para consultas académica de los alumnos y el manejo de procesadores de texto tal como el Microsoft Word.

Los principales objetivos de la propuesta presentada fueron:

Analizar el uso de las herramientas tecnológicas en los procesos de enseñanza de aprendizaje en el marco de la metodología de Enseñanza para la Comprensión.

Evaluar la aplicación de simuladores en la construcción de conocimiento asociado a los procesos de evolución.

Las simulaciones son una herramienta muy utilizada en el trabajo científico profesional dado que permiten representar y analizar fenómenos complejos y poner a prueba teorías e innovaciones (Furman y
Podesta, 2009). Esta herramienta brinda la posibilidad de concentrarse en los datos proporcionados por la simulación para emprender actividades de análisis más profundo. Además, son ventajosas porque brindan elementos concretos que permiten el desarrollo de competencias científicas valiosas como el análisis de datos, elaboración de predicciones a partir de hipótesis, la búsqueda de evidencias para sostener una idea, etc. En síntesis, la aplicación del método científico. Por otro lado es una herramienta útil para trabajar con grupos numerosos y con limitaciones temporales en clases presenciales.

Considerando que uno de los principios unificadores de la biología es la Evolución, resulta indispensable la comprensión de este eje temático desde los inicios en la formación de las carreras biológicas. En el Plan de estudios de la FACENA, el abordaje inicial de esta temática se da en la Asignatura Introducción a la Biología.Desde el enfoque convencional de este tópico en los trabajos prácticos se observaron dificultades en la comprensión del mismo. Por lo que se incorporó la innovación con la aplicación de simuladores.

Durante el desarrollo del trabajo práctico de simulación el alumno es el principal actor de la clase, siendo el eje vertebrador de la misma la aplicación del Método Científico Hipotético-deductivo, desarrollado previamente. Los alumnos se organizan en grupos de trabajo, e inician la actividad con el planteo de hipótesis y diseño de experimentación que luego ponen a prueba en el software del simulador (Figura 1). 

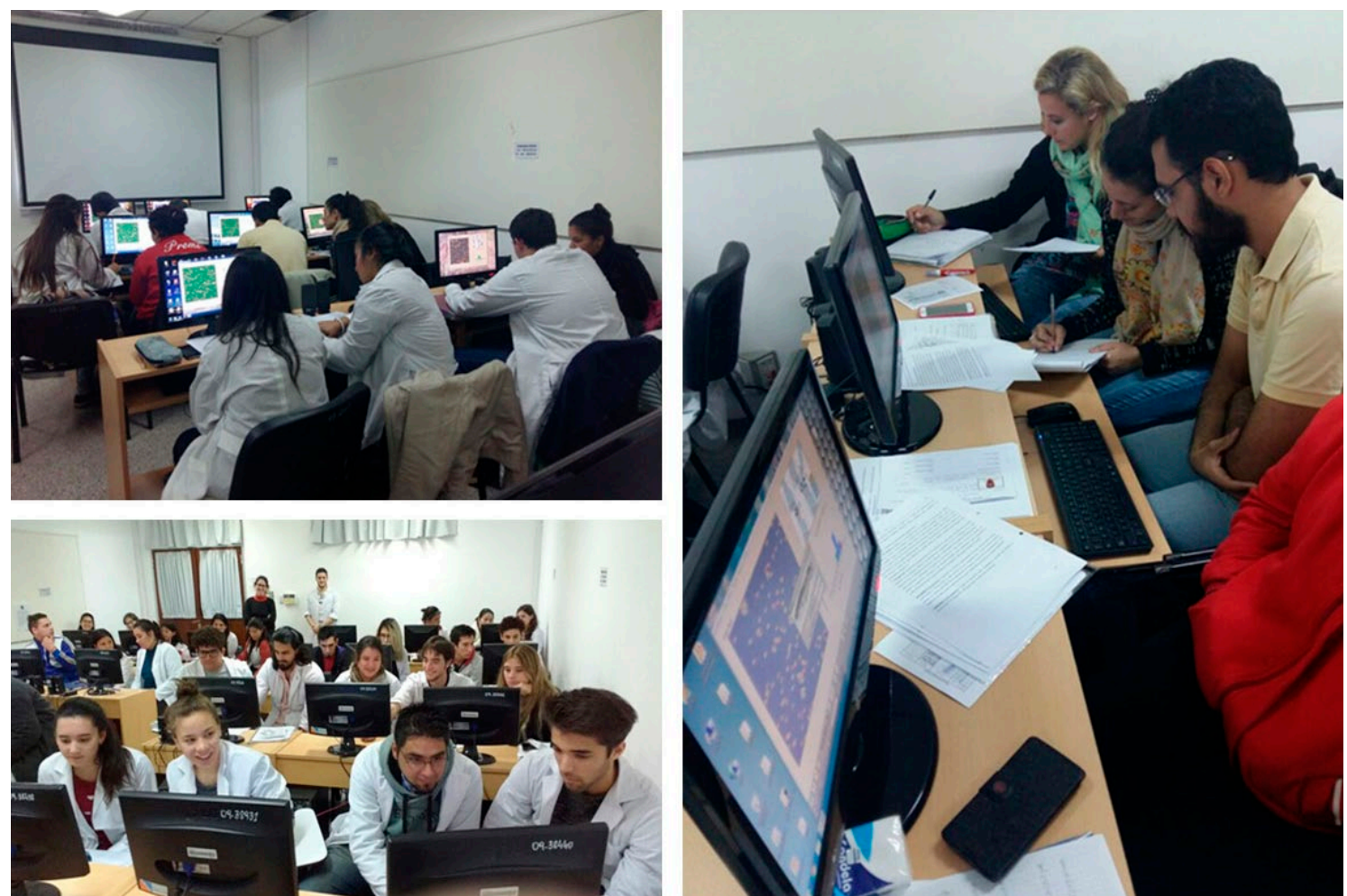

Fig. 1. Alumnos de Introducción a la Biología, cohorte 2017, durante el desarrollo del Trabajo Práctico de Simulación.

Finalmente, los resultados son expues- dos conceptuales que se desarrollan se destos por cada grupo en una puesta en común. tacan parámetros poblacionales, genética, La principal ventaja de la aplicación de esta neodarwinismo, importancia de la escala TIC es la facilidad de integración y trabajo temporal y tipos de selección sexual y natusimultaneo de conceptos, procedimientos y ral. Por otro lado, la construcción y manejo actitudes del alumnado. Entre los conteni- de histogramas, la facilidad de interpreta-
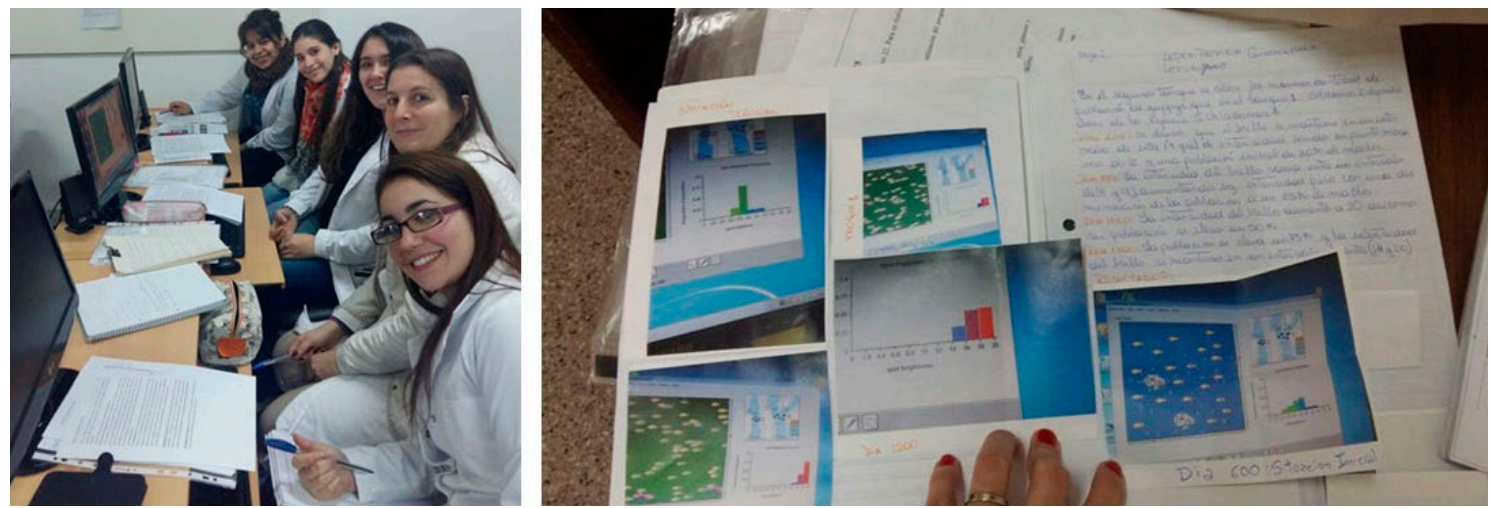

Fig. 1. Alumnos de Introducción a la Biología, cohorte 2017,

durante el desarrollo del Trabajo Práctico de Simulación. 
ción de resultados por el soporte gráfico del software, la aplicación de los sucesivos pasos del método científico, redacción de informes son los contenidos procedimentales más importantes (Figura 2). Mientras que, el trabajo colaborativo, cuidado del equipamiento informativo de la institución, alta motivación y la participación individual y grupal fueron las actitudes más destacadas.

\section{RESULTADOS}

El uso de esta herramienta permitió consolidar el proceso de transferencia de los tres contenidos tanto desde el tópico de evolución como el de ecología. Además, en el desarrollo de seminarios posteriores se evidenció un incremento en la utilización de una variedad de TICS como herramientas didácticas; particularmente el uso de Power Point, PREZI, videos, imágenes en formato gift. Esto refleja una superación del aprendizaje memorístico respondiendo a modelos positivistas. La profundidad en la comprensión de la temática se vio reflejada, además, en mejores desempeños de los alumnos en las evaluaciones parciales y finales de la asignatura. Particularmente cuando el alumnado utiliza el trabajo práctico de simulación y seminarios para explicar y hacer transferencia en diferentes situaciones. Finalmente, los resultados obtenidos hasta el momento fueron muy positivos, tanto desde la participación individual en clase hasta las puestas en común y utilización de las herramientas Tics en la elaboración de seminarios sobre la temática. A partir de una situación problemática vinculada a poblaciones de organismos que muestran diferentes características fenotípicas y condiciones ambientales.

\section{CONCLUSIONES}

- A modo de reflexiones finales, y a partir de lo que se viene trabajando y concretando a lo largo deestos años, con los alumnos de las diferentes cohortes de Introducción a la Biología, es pertinente poner el acento en la importancia que tiene, brindar la posibilidad de desarrollar talleres de utilización de las TIC en áreas específicas, ya que los estudiantes de nivel superior en general manejan adecuadamente las TIC, pero, desconocen la importancia del uso y manejo pertinente en la asignatura biología y su incorporación a los TP.

- Las TICs ocupan un lugar importante en la vida cotidiana de los estudiantes, sin embargo, la variedad utilizada con fines académicos es muy acotada.

- Representan una herramienta didáctica importante en la secuencia de todas las etapas que el alumno va construyendo su propio aprendizaje, desde la fijación y comprensiónhasta la transferencia de contenidos conceptuales, procedimentales y actitudinales.

- Son herramientas pertinentes y motivadoraspara el proceso de enseñanza en alumnos de primer año de las carreras biológicas.

- El uso de simuladores mejoró la construcción de conocimiento relacionado con la evolución como principio unificador de la biología. 
Por lo antes mencionado, coincidimos que la sociedad actual está expuesta y accede rápidamente a las TIC, lo que requiere en igual medida es la guía, acompañamiento y asesoramiento para que los resultados de su incorporación al ámbito educativo promuevan ambientes de aprendizajes activos y prácticos, con sujetos críticos, reflexivos y colaborativos, propiciando que los procesos de enseñanza y aprendizaje resulten adecuados y significativos para los estudiantes.

Tabla 1: Indicadores de Utilización de TICS en cohorte 2017 de alumnos regulares de la Asignatura Introducción a la Biología.

Categorías: 1-4 (> $25 \%$; 25-50 \%; 50-75 \%, > $75 \%$ ).

\begin{tabular}{|l|c|c|}
\hline \multicolumn{1}{|c|}{ Indicadores } & CATEGORIA USO & \% Total \\
\hline Uso diario Internet & 4 & 96 \\
\hline Uso YouTube como consulta/documentales & 4 & 81 \\
\hline Manejo de Procesador Texto (Word) & 4 & 91 \\
\hline Uso frecuente @mail & 3 & 55 \\
\hline Uso UNNE VIRTUAL- 2 a 3 veces/semana & 3 & 56 \\
\hline Uso Encuestas ON LINE & 3 & 58 \\
\hline Uso de Facebook & 3 & 70 \\
\hline Uso de otras redes sociales & 3 & 62 \\
\hline Uso Teléfono en clase para consultas académicas & 3 & 64 \\
\hline Uso Presentaciones (Power Point) & 3 & 59 \\
\hline Lectura de libros digitales & 3 & 59 \\
\hline Documentales en TV & 3 & 62 \\
\hline Uso Google Drive & 2 & 36 \\
\hline Uso de Google Earth & 2 & 35 \\
\hline Uso Hoja Cálculo (Excel) & 2 & 31 \\
\hline Uso Wikis & 2 & 48 \\
\hline Uso frecuente de mensajes texto & 2 & 37 \\
\hline No Uso Internet & 1 & 4 \\
\hline Uso UNNE VIRTUAL- Diario & 1 & 20 \\
\hline Uso UNNE VIRTUAL - al menos 1 vez/semana & 1 & 3 \\
\hline Uso Foros ON LINE & 1 & 11 \\
\hline Uso Programa simulación (no lúdicos) & 1 & 7 \\
\hline Consultar Google Académico & 1 & 19 \\
\hline Uso de PREZI & 1 & 21 \\
\hline Carga en espacios Wikis & 1 & 1 \\
\hline
\end{tabular}




\section{REFERENCIAS BIBLIOGRÁFICAS}

Furman, M. y M.E. Podesta. 2009. La aventura de enseñar Ciencias Naturales. Buenos Aires: AIQUE. Capítulo 1 disponible en línea en: http://noticias.ar.sangari.com/download/cienciasnaturales.pdf

Manso, M.; P. Pérez; M. Libedinsky; D. Light; M. Garzón. 2011. Las TIC en las aulas. Experiencias Latinoamericanas. 1ra edición. Editorial Paidós. Buenos Aires. Argentina.

Mautino, J.M. 2008. Didáctica de la educación tecnológica. Como aprender, como enseñar. Primera Edición. Buenos Aires. Editorial Bonum. 166 p.

Pogré, P. 2009. Enseñanza para la comprensión, un marco para innovar en la intervención didáctica. En: Escuelas del futuro II. Cómo planifican las escuelas que innovan. Educación Papers Editores. Cap. 3.101-124

Salomon, P. 2012. Enseñando Biología con las TIC. Integración de la Tecnología Educativa en el aula. Editorial CengageLearning. 241 p. Buenos Aires. Argentina. 